\title{
A new class of yb203 doped nano-structured multi-element silica glass based optical fiber for fiber laser
}

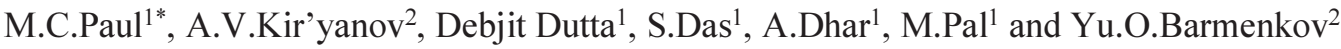 \\ ${ }^{1}$ Fiber Optics and photonic division, CSIR-Central Glass \& Ceramic Research Institute, \\ 196, Raja S.C. Mullick Road, Kolkata-700 032, India. \\ ${ }^{2}$ Centro de Investigaciones en Optica, Loma del Bosque 115, Col. Lomas del Campestre, Leon, \\ Guanajuato, Mexico \\ *Email:mcpal@cgcri.res.in
}

We report on development of $\mathrm{Yb}_{2} \mathrm{O}_{3}$ doped nanostructured multi-elements silica glass based optical fiber along with material characterization for high power fiber laser showing very good lasing efficiency with low photodarkening (PD) phenomenon which take place via charge transfer mechanism with minimization of concentration quenching effect followed by stabilization of $\mathrm{Yb}^{3+}$ ions compared to commercial available $\mathrm{Yb}$ doped fibers based on alumina-phospho silica glass.

A new class of $\mathrm{Yb}^{3+}$-doped nano-engineered calcium stabilized zirconia alumina-phospho silica multi-elements glass based fiber preform was made using the modified chemical vapor deposition (MCVD) process, followed by the solution doping technique [1-2]. The main choice of such kind of doping host of $\mathrm{Yb}_{2} \mathrm{O}_{3}$ is to increase the absorption as well as emission cross-section of $\mathrm{Yb}$ ions providing good thermal and mechanical property along with increase of the solubility of rare-earths ions and to increase the optical transparency of glass in the UV region. The fiber parameter of newly developed fiber and commercial fiber are given in Table 1 .

Table 1: Fiber parameters

\begin{tabular}{|c|c|c|c|c|}
\hline \multicolumn{2}{|c|}{ Core composition } & $\begin{array}{c}\text { Core } \\
\text { diameter }\end{array}$ & $\mathrm{NA}$ & $\begin{array}{c}\text { Cladding } \\
\text { absorption at } \\
976 \mathrm{~nm}\end{array}$ \\
\hline $\mathrm{MEP}-\mathrm{Yb}$ & $\begin{array}{l}\mathrm{SiO}_{2}-\mathrm{Yb}_{2} \mathrm{O}_{3}- \\
\mathrm{P}_{2} \mathrm{O}_{5}-\mathrm{Al}_{2} \mathrm{O}_{3}- \\
\mathrm{ZrO}_{2}-\mathrm{Ce}_{2} \mathrm{O}_{3}- \\
\mathrm{CaO}\end{array}$ & 11.2 & 0.15 & 6.0 \\
\hline $\mathrm{C}-\mathrm{Yb}$ & $\begin{array}{l}\mathrm{SiO}_{2}-\mathrm{Yb}_{2} \mathrm{O}_{3}- \\
\mathrm{P}_{2} \mathrm{O}_{5}-\mathrm{Al}_{2} \mathrm{O}_{3}\end{array}$ & 11.0 & 0.08 & 5.5 \\
\hline
\end{tabular}

The nano-phase separated host was retained into the silica glass matrix at the fiber drawing stage as confirmed from TEM analyses along with electron diffraction patterns, shown in Figure 1. The average particle size is around $5 \pm 2 \mathrm{~nm}$ and the black spots in the TEM image illustrate the phase-separated nanoparticles region. The nature of the phase-separated particles was found to be partially crystalline confirmed by their electron diffraction pattern shown in the inset of Figure 1(a).

Achieved 16.0 W output power having 80\% lasing efficiency with low photo-darkening phenomena compared to available commercial fiber shown in Figure 1(b) and Figure 1(c) respectively. Yb doped multi elements silica glass based fiber shows low photodrakening al least $20 \%$ less than that of standard phospho-alumina silica glass based $\mathrm{Yb}$ doped fiber. In such kind of glass host, the enhanced $\mathrm{PD}$ resistivity takes place through multiple effects via charge transfer mechanism of $\mathrm{Ce}^{3+}$ to $\mathrm{Ce}^{4+}$ within nano-phase separated region, minimization of concentration quenching effect of $\mathrm{Yb}$ ions in presence of $\mathrm{Al}^{3+}, \mathrm{P}^{5+}, \mathrm{Zr}^{4+}$ by preventing formation of $\mathrm{Yb}-\mathrm{Yb}$ bonds along with stabilization of $\mathrm{Yb}^{3+}$ ions by divalent calcium ions under high power irradiation.

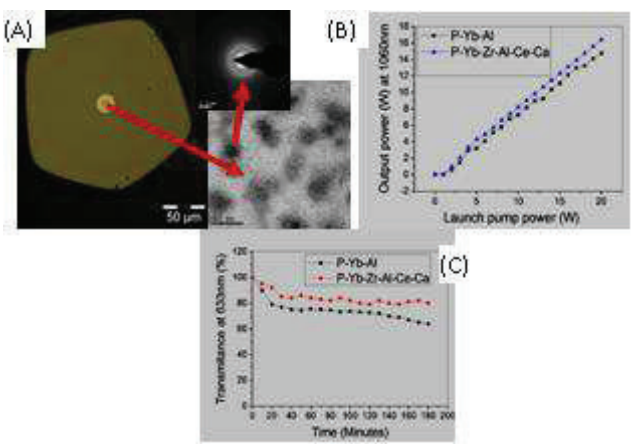

Figure 1: (A) The fiber cross-sectional view along with TEM and electron diffraction pattern, (B) Lasing performance and (c) photodarkening phenomena

Acknowledgements: Authors are thankful for financial support from Department of Science \& Technology, Govt. of India

\section{References}

1. J.E.Townsend, S.B.Poole and .D.N.Payne Electron.Lett. 23, 329(1987)

2. K. Thambiratnam, A. Z. Zulkifli, and M. C. Paul, Opt. Mater. Express, 2, 1690 (2012) 